\title{
Development and external validation of a nomogram for predicting the effect of tumor size on cancer specific survival of resected gallbladder cancer: a population-based study.
}

\section{Yaodong Zhang}

The First Affiliated Hospital of Nanjing Medical University

\section{Tao Zhou}

The First Affiliated Hospital of Nanjing Medical University

\section{Sheng Han}

The First Affiliated Hospital of Nanjing Medical University

\section{Yirui Wang}

The First Affiliated Hospital of Nanjing Medical University

\section{Jiang Chang}

The First Affiliated Hospital of Nanjing Medical University

\section{Wangjie Jiang}

The First Affiliated Hospital of Nanjing Medical University

\section{Ziyi Wang}

The First Affiliated Hospital of Nanjing Medical University

\section{Changxian Li}

The First Affiliated Hospital of Nanjing Medical University

Xiangcheng Li ( $\nabla$ drxcli@njmu.edu.cn )

The First Affiliated Hospital of Nanjing Medical University

\section{Research}

Keywords: Gallbladder Cancer, Tumor size, Nomogram, SEER

Posted Date: August 19th, 2020

DOI: https://doi.org/10.21203/rs.3.rs-57305/v1

License: (c) (i) This work is licensed under a Creative Commons Attribution 4.0 International License. Read Full License 
Version of Record: A version of this preprint was published at International Journal of Clinical Oncology on March 5th, 2021. See the published version at https://doi.org/10.1007/s10147-021-01891-2. 


\section{Abstract \\ Background \& Aims:}

The impact of tumor size on account of the long-term survival results in gallbladder cancer (GBC) patients has been controversial. It is urgent necessary to identify the optimal cutoff value of tumor size in resected $\mathrm{GBC}$, and we attempted to integrate tumor size with other prognostic factors into a prognostic nomogram to predict the cancer-specific survival (CSS) of GBC patients.

\section{Methods}

1639 patients with resected GBC were extracted from the Surveillance, Epidemiology and End Results (SEER) database. X-tile program was used to identify the optimal cutoff value of tumor size. A nomogram including tumor size was established to predict 1-, 3- and 5-year CSS based on the independent risk factors chosen by univariate and multivariable cox analyses. The precision of the nomogram for predicting survival was validated with Harrell's concordance index (C-index), calibration curves, and receiver operating characteristic curve (ROC) internally and externally.

\section{Results}

Patients with GBC were classified into 1-13 mm, 14-63 mm and $64 \mathrm{~mm}$ subgroup based on the optimal cutoff for tumor size in terms of CSS. The nomogram according to the independent factors was well calibrated and displayed better discrimination power than 7th Tumor-Node-Metastasis (TNM) stage systems.

\section{Conclusions}

The results demonstrated that increased tumor size is closely associated with the worse CSS. Our novel nomogram, which outperforms the conventional TNM staging system, showed satisfactory accuracy and clinically practicality for predicting the outcome of resected GBC patients.

\section{Introduction}

Gallbladder carcinoma (GBC) is a rare, lethal malignancy characterized by its vague symptoms at initial stage, less than one-third of patients presenting are eligible for curative-intent surgical resection and only $16 \%$ patients with GBC will survive for more than five years ${ }^{1-4}$. Because of the lack of a serosal layer of gallbladder adjacent to the liver, direct hepatic parenchymal invasion and metastasis are the major cause of its dismal prognosis 5 . 
Unlike lymph node metastasis and liver invasion, which have been recognized as the independent prognostic factors in GBC, the impact of tumor size on the long-term survival results in GBC patients, especially those who underwent resection, has remained a controversial debate in worldwide. The wideaccepted standard Tumor-Node-Metastasis (TNM) staging system of the American Joint Commission on Cancer (AJCC) mainly relies on pathological evaluation of tumor infiltration into the layers of gallbladder, which can only be achieved through surgical excision of the gallbladder and didn't take tumor size into account $^{6}$. The recent studies, which proposed prognostic nomograms/systems, pointed out that patient and tumor-related factors are closely associated with prognosis of GBC patients ${ }^{7,8}$. Notably, several studies have found that tumor size, as an easily quantifiable indicator in imaging diagnosis and preoperative assessment, can affect the survival outcome of GBC patients ${ }^{7-9}$. However, the optimal cutoff value of tumor size for predicting prognosis of GBC is still controversial. Yadav staging system set tumor size larger than $5 \mathrm{~cm}$ as a factor indicated survival disadvantage, whereas Zhang labeled $3 \mathrm{~cm}$ as an important prognostic factor 7,8 . In addition, no further studies were conducted to identify the association between the tumor size and other tumor-related factors, such as tumor grade and liver metastasis. Therefore, we sought to explore the prognostic value of tumor size in GBC based on data from Surveillance, Epidemiology, and End Results (SEER) Program of the National Cancer Institute, and assessed the ability of the novel prognostic model using the data from our own center.

The well-established nomograms are increasingly becoming decision-making aids for predicting individual risk evaluation and therapeutic outcomes ${ }^{10}$. Compared to the current TNM staging system, we aim to establish a novel prognostic nomogram incorporated important factors for predicting the cancer-specific survival (CSS) of GBC patients after surgical resection based on the tumor size using SEER database. Validation was performed to evaluate the accuracy of the predictive model using an internal validation set derived from the random set of SEER databases and an external validation set from First Affiliated Hospital of Nanjing Medical University, as representative of the Asian population.

\section{Methods}

\section{Population and covariates}

Information of patients initially diagnosed with GBC between 2010 and 2016 was extracted from the SEER-18 database using SEER $*$ Stat software version 8.3.6. Eligible GBC patients were identified according to the International Classification of Diseases for Oncology, Third Revision (ICD-0-3) codes reported on AJCC Cancer Staging Manual 2017:

$8010,8148,8503,8470,8140,8144,8480,8310,8490,8070,8560,8020,8246,8041,8013,8244$. We limited our analysis to the primary GBC patients with confirmed pathological examination (positive exfoliative or histology) and available complete follow-up dates. To ensure an adequate number of samples for analysis and explore the prognostic value of tumor size for patients after surgical resection, we also excluded patients with the following incomplete information: tumor size, not perform the surgical resection, tumor grade, race, regional nodes examined and positive, TNM stage. The detailed workflow for patient selection is shown in Fig. 1. To estimate the generalizability of the novel nomogram, we performed the separate 
external validation using 46 eligible GBC diagnosed in the First Affiliated Hospital of Nanjing Medical University. The clinicopathological features of all patients are shown in Table 1. The investigation was approved by the ethics committee of the First Affiliated Hospital of Nanjing Medical University.

\section{Definition of variables}

Demographic and clinical variables of 1639 patients fulfilling the inclusion criteria were obtained from the SEER database. Age was divided into $<60$ and $\geq 60$ years old. Tumor grade was regrouped as well/moderately differentiated and poorly differentiated/undifferentiated. Regional nodes examined was listed as $\geq 6,1-5$ and 0 according to the recommendations in the 8th AJCC staging system. And regional nodes positive was stratified as $0,1-3, \geq 4$ and no examined as recommended by the 8th TNM staging system. CSS was set as the primary outcome of patients with GBC, and time of CSS was counted from data of diagnosis to death due to GBC.

\section{Nomogram development and Statistical analyses}

The included patients were randomized into a training cohort $(n=1103)$ and a validation cohort $(n=536)$ at a ratio of 7:311,12. Eight clinicopathological features, including age, race, sex, tumor grade, $T$ stage, $M$ stage, regional nodes examined and regional nodes positive were applied to analysis. Cox proportional hazard models were used to screen the independent risk factors to construct nomograms for predicting 1-,3- and 5-year CSS. The construct nomogram was subjected validation through 500 bootstrap resamples in the internal and external validation cohort. The area under receiver operating characteristic (ROC) curve (AUC) and the consistency index (C-index) were used to verify the precision of nomogram ${ }^{13,14}$. Calibration plotting was used to evaluate the agreement between the actual outcome and the predicted probability ${ }^{15}$. The age-standardized incidence of GBC was expressed as per 100,000 individuals using the 2000 US Standard Population. Annual percentage change (APC) in the incidence was calculated using the weighted least squares method ${ }^{16}$. Statistical analysis was conducted using R software 3.6.2 ( $R$ foundation, Vienna, Austria) and SPSS version 21.0 (SPSS Inc., Chicago, IL, USA). A two tailed P-value < 0.05 was considered statistically significant.

\section{Results}

\section{Incidence trends}

Generally, the overall age-adjusted incidence of GBC continued to increase with an APC of $1.19 \%$ between 1978-1993(Fig. 2A). During this period of increased incidence of GBC, the incidence increased steeply from 1989 to 1992 with an APC of $4.17 \%$, whereas it turned to decrease since 1992 . The incidence rate in males was basically consistent with the overall trend in the whole population (Fig. 2B). Notably, the ageadjusted incidence rate of this disease in females significantly decreased over time (Fig. 2C). Among the previous studies, sex was deemed as the prognostic factor in the progression of GBC. Considering the decline in the incidence among women since 1975, we speculated that there may be gender differences in the incidence of GBC. 


\section{Patients' characteristics}

A total of 1103 patients diagnosed with GBC were included in the training set, and 536 patients were enrolled in the validation set. The external validation cohort include 46 patients from the first affiliated hospital of Nanjing medical university. The descriptive and clinical characteristics of these patients are listed in Table.1. Overall, in training cohort, a large proportion of the patients (75.2\%) were older than 60 years. Well and moderate differentiation $(n=631,57.2 \%)$ were the most common tumor grade. A total of $268(24.3 \%)$ patients had regional lymph nodes metastasis, and 34 (3.1\%) patients had four or more regional lymph nodes positive.

\section{Identification of optimal tumor-size cutoff value with prognosis}

The cutoff value, $14 \mathrm{~mm}$ and $64 \mathrm{~mm}$, of tumor size was identified by X-tile plot based on minimal P-value approach and the maximum of chi-square log-rank values was 107.2 according to CSS (Fig. 3A). To validated the effect of tumor size on CSS, we divided patients from training cohort and internal validation cohort into three risk groups using $14 \mathrm{~mm}$ and $64 \mathrm{~mm}$ as the cutoff value (Fig. 3B\&C). The results showed that tumor size is closely associated with the prognosis of GBC patients with resection, and patients with $14 \mathrm{~mm}$ or less $\mathrm{GBC}$ had better prognosis, and tumor size larger than $64 \mathrm{~mm}$ is a significant negative factor implying a worse prognosis. To better reveal the clinical value of this tumor-size cutoff value, we compared the differences in tumor characteristics among the three groups. Of these, we found that increased tumor size group is associated with poor tumor grade, advanced T stage, more distant metastasis, more regional lymph nodes examined and positive, and more frequency liver metastasis (Table.2, all $p<0.05$ ).

\section{Effect of tumor size counts on survival outcome of GBC}

In the training cohort, the univariate cox analysis showed that, besides of tumor size, age, tumor grade, $T$ stage, $M$ stage, regional nodes examined and regional nodes positive were also identified as statistically significant prognostic factors (Table 3.all $\mathrm{P}<0.05$ ). All these significant factors were subjected to the multivariate cox analysis to identify independent predictors of survival for patients. Using multivariate cox analysis of training cohort, age, tumor grade, $\mathrm{T}$ stage, $\mathrm{M}$ stage, regional nodes examined, regional nodes positive and tumor size were found to be independent risk factor $s$ in terms of CSS of GBC patients with surgical resection (Table 3.all $P<0.05$ ).

\section{Construction and Validation of Prognostic Nomogram for CSS}

Prognostic nomograms for GBC were constructed based on the seven independent prognostic variables for CSS from the training cohort (Fig. 4). The nomogram showed that T stage contributed most to CSS, and notably, the effect of tumor size on prognosis was basically the same as that of tumor grade and number of positive regional lymph nodes, which were widely accepted as the important factors in 
prognosis of GBC. And we were able to calculated the total risk point to estimate the 1-,3- and 5-year CSS according to the survival probability scales in the nomogram. C-index and ROC curves are ordinarily used to evaluate the discriminatory power of a nomogram. In the internal and external validation cohort, the nomogram discriminatory accuracy of the nomogram for CSS prediction were superior to that of either the 7th edition TNM stage systems (Internal validation: 0.731 vs 0.689 ; External validation: 0.654 vs 0.533 , Fig. 4).

The discriminatory capacity of the nomograms and 7th edition TNM stage systems was compared by analyzing the AUC values (Fig. 5). In the internal validation, the AUC values of nomogram predicting 1-, 3-, and 5-year CSS rates were $0.793,0.821$ and 0.825 , whereas the AUC values were $0.715,0.765$ and 0.799 , respectively for the 7th edition TNM stage system. These results showed that the novel nomogram had better accuracy for predicting the CSS than that with the 7th TNM stage system. In the external cohort, we also found that 1-and 3-year AUC value of the nomogram showed optimal accuracy for predicting the CSS compared with the 7th TNM stage system (1-year: 0.737 vs 0.487 ; 3-year: 0.785 vs 0.617 , Fig. 5 ).

\section{Discussion}

With lack of specific symptoms and early screening methods, GBC remains a highly malignant tumor with a discouraging prognosis ${ }^{17,18}$. Consistent with previous studies regarding the incidence of gallbladder cancer, we also found that overall incidence of GBC decreased in USA ${ }^{19}$. Notably, the incidence rates of GBC in male was similar to the overall incidence trend but significant declined year by year among woman. These findings showed variation in incidence patterns of GBC by sex, supporting the notion that GBC should be considered separately in different genders because of female reproductive factors proposed by Zhang et $\mathrm{al}^{20}$. The accurate prognostic information is necessary for surgeon to make better clinical decisions and perform consultations with patients regarding life expectancy after surgical resection. Currently, TNM staging system is still an internationally recognized guideline for predicting GBC prognosis. However, TNM staging system is mainly based on accurate pathological assessment and not included patient-related factors. These factors and other clinical parameters may be helpful in predicting GBC patient outcomes, especially for the patients with surgical resection. The significance of tumor size, an easily quantifiable indicator in imaging diagnosis and preoperative assessment, in GBC prognosis is still controversial worldwide. The current AJCC TNM staging system didn't include tumor size as the prognostic factor in GBC. Several studies several studies have found that tumor size may be an independent prognosis factor in GBC, which is in line with our study, however, debate also exists regarding the optimal cutoff value of tumor size in GBC. Yadav et al. reported that tumor size larger than $5 \mathrm{~cm}$ exert prognostic significance for GBC patients ${ }^{8}$. Zhang et al. demonstrated that tumor size smaller than $3 \mathrm{~cm}$ obviously increase the survival outcome of GBC patients ${ }^{7}$. To address this issue, we first used the X-tile program to divided GBC patients into low, middle, and high-risk groups, and identified $14 \mathrm{~mm}$ and $64 \mathrm{~mm}$ as the optimal cutoff value in terms of GBC, and established a more accurate and effective survival model to predict the prognosis of patients after surgical resection based on the tumor size. Notably, our results demonstrated that increased tumor size group is associated with poor tumor grade, advanced T stage, 
more distant metastasis, more regional lymph nodes examined and positive, and more frequency liver metastasis.

It is crucial to determine the generalizability and preventing overfitting of the novel prediction model by internal and external validation. The calibration plots of our scoring system demonstrated the best consistency between the nomogram predicted and actual observed 1-, 3- and 5-year CSS in both the SEER cohort and the external cohort. Our nomogram also demonstrated better indicating better prognostic performance compared with the AJCC TNM staging system. Remarkably, our nomogram strengthened again the role of tumor size in influencing the survival of GBC patients underwent resection.

This study has limitations inherent to its retrospective nature. First, some potential prognostic factors, such as neoadjuvant therapies, were not available in the SEER dataset and were therefore not included in the nomograms as the evaluation of such variables could not be carried out in this study ${ }^{21}$. Second, although a large cohort and single-center external validation were available for this study, further external validations based on more large-scale cohorts will seek to test our model performance.

\section{Conclusions}

In conclusion, we demonstrated that tumor size was an independent factor in predicting the CSS of GBC patients after resection. Increased tumor size was associated with poor tumor grade, advanced T stage, more distant metastasis, more regional lymph nodes examined and positive, and more frequency liver metastasis in GBC. We created a novel nomogram, which has been constructed and external validated, for patients with GBC based on tumor size at the time of diagnosis. We found this system to be superior to the AJCC TNM staging system in predicting CSS in patients with surgical resection.

\section{Abbreviations}

GBC: Gallbladder Cancer; CSS: cancer-specific survival; SEER: the Surveillance, Epidemiology and End Results database; ROC: receiver operating characteristic curve; APC: Annual percentage change.

\section{Declarations}

\section{Ethics approval and consent to participate}

The investigation was approved by the ethics committee of the First Affiliated Hospital of Nanjing Medical University. Consent was waived considering the anonymous, observational, population-based, and registrybased nature.

\section{Consent for publication}

Not applicable. 
The data that support the findings of this study are available from each participating registry but restrictions apply to the availability of these data, which were used under license for the current study, and so are not publicly available.

\section{Conflicts of interest}

The authors declare that they have no competing interests.

\section{Funding}

This study was supported by Natural Science Foundation of Jiangsu Province, China (BK20171077) and Key research and development program of Jiangsu Province (BE2016789), National Science Foundation of China (NSFC) (81700572, 81670570), National Science and Technology Major Project of China (2017ZX10203207-004-004囚. The funder had no involvement in study design; in the collection, analysis, or interpretation of data; in the writing of the report; or in the decision to submit the paper for publication.

\section{Authors' contributions}

Conception or design were provided by XCL and YDZ. Acquisition, analysis, or interpretation of data were supplied by YDZ, TZ and SH. Drafting of the manuscript was done by YDZ and TZ. Critical revision of the manuscript for important intellectual content was imparted by YRW and JC. Statistical analysis was contributed by WJJ and ZYW. Administrative, technical, or material support was provided by CXL. All authors have given the final approval of the manuscript for submission and publication.

\section{Acknowledgements}

We are very grateful to the staff in Surveillance, Epidemiology, and End Results Program (SEER) for their kind work in data collection and delivery.

\section{References}

1. Lau CSM, Zywot A, Mahendraraj K, Chamberlain RS. Gallbladder Carcinoma in the United States: A Population Based Clinical Outcomes Study Involving 22,343 Patients from the Surveillance, Epidemiology, and End Result Database (1973-2013). HPB surgery: a world journal of hepatic, pancreatic and biliary surgery 2017, 1532835, doi:10.1155/2017/1532835 (2017).

2. Smith GC, Parks RW, Madhavan KK, Garden OJ. A 10-year experience in the management of gallbladder cancer. HPB: the official journal of the International Hepato Pancreato Biliary Association. 2003;5:159-66. doi:10.1080/13651820310000037.

3. Shukla SK, Singh G, Shahi KS, Bhuvan \& Pant P, Staging. Treatment, and Future Approaches of Gallbladder Carcinoma. Journal of gastrointestinal cancer. 2018;49:9-15. doi:10.1007/s12029-0170036-5.

4. Baiu I, Visser B. Gallbladder Cancer Jama. 2018;320:1294. doi:10.1001/jama.2018.11815. 
5. Hundal R, Shaffer EA. Gallbladder cancer: epidemiology and outcome. Clinical epidemiology. 2014;6:99-109. doi:10.2147/CLEP.S37357.

6. Chun YS, Pawlik TM, Vauthey JN. 8th Edition of the AJCC Cancer Staging Manual: Pancreas and Hepatobiliary Cancers. Ann Surg Oncol. 2018;25:845-7. doi:10.1245/s10434-017-6025-x.

7. Zhang W, Hong HJ, Chen YL. Establishment of a Gallbladder Cancer-Specific Survival Model to Predict Prognosis in Non-metastatic Gallbladder Cancer Patients After Surgical Resection. Digestive diseases sciences. 2018;63:2251-8. doi:10.1007/s10620-018-5103-7.

8. Yadav S, et al. A Novel Clinically Based Staging System for Gallbladder Cancer. Journal of the National Comprehensive Cancer Network: JNCCN. 2020;18:151-9. doi:10.6004/jnccn.2019.7357.

9. Cen D, et al. Clinicopathological features and survival for gallbladder NEN: a population-based study. Endocrine connections. 2019;8:1273-81. doi:10.1530/EC-19-0124.

10. Freedman AN, et al. Cancer risk prediction models: a workshop on development, evaluation, and application. J Natl Cancer Inst. 2005;97:715-23. doi:10.1093/jnci/dji128.

11. Collins GS, Reitsma JB, Altman DG, Moons KG. Transparent reporting of a multivariable prediction model for individual prognosis or diagnosis (TRIPOD): the TRIPOD statement. Bmj. 2015;350:g7594. doi:10.1136/bmj.g7594.

12. Lei $Z$, et al. Nomogram for Preoperative Estimation of Microvascular Invasion Risk in Hepatitis B Virus-Related Hepatocellular Carcinoma Within the Milan Criteria. JAMA surgery. 2016;151:356-63. doi:10.1001/jamasurg.2015.4257.

13. Chen S, et al. Development and Validation of a Nomogram for Predicting Survival in Male Patients With Breast Cancer. Frontiers in oncology. 2019;9:361. doi:10.3389/fonc.2019.00361.

14. Hanley JA, McNeil BJ. The meaning and use of the area under a receiver operating characteristic (ROC) curve. Radiology. 1982;143:29-36. doi:10.1148/radiology.143.1.7063747.

15. Coutant $C$, et al. Comparison of models to predict nonsentinel lymph node status in breast cancer patients with metastatic sentinel lymph nodes: a prospective multicenter study. Journal of clinical oncology: official journal of the American Society of Clinical Oncology. 2009;27:2800-8. doi:10.1200/JCO.2008.19.7418.

16. Feng J, et al. Incidence trends and survival prediction of hepatoblastoma in children: a populationbased study. Cancer communications. 2019;39:62. doi:10.1186/s40880-019-0411-7.

17. Aloia TA, et al. Gallbladder cancer: expert consensus statement. HPB: the official journal of the International Hepato Pancreato Biliary Association. 2015;17:681-90. doi:10.1111/hpb.12444.

18. Randi G, Franceschi S, La Vecchia C. Gallbladder cancer worldwide: geographical distribution and risk factors. International journal of cancer. 2006;118:1591-602. doi:10.1002/ijc.21683.

19. Sharma A, Sharma KL, Gupta A, Yadav A, Kumar A. Gallbladder cancer epidemiology, pathogenesis and molecular genetics: Recent update. World journal of gastroenterology. 2017;23:3978-98. doi:10.3748/wjg.v23.i22.3978.

20. Zatonski WA, et al. Epidemiologic aspects of gallbladder cancer: a case-control study of the SEARCH Program of the International Agency for Research on Cancer. J Natl Cancer Inst. 1997;89:1132-8. 
doi:10.1093/jnci/89.15.1132.

21. Wang SJ, et al. Nomogram for predicting the benefit of adjuvant chemoradiotherapy for resected gallbladder cancer. Journal of clinical oncology: official journal of the American Society of Clinical Oncology. 2011;29:4627-32. doi:10.1200/JC0.2010.33.8020.

\section{Tables}




\begin{tabular}{|c|c|c|c|c|c|c|c|}
\hline \multicolumn{8}{|c|}{ Table.1 Patients characteristics } \\
\hline \multicolumn{2}{|l|}{ Characteristic } & \multicolumn{2}{|c|}{ Training cohort } & \multicolumn{2}{|c|}{$\begin{array}{l}\text { Internal validation } \\
\text { cohort }\end{array}$} & \multicolumn{2}{|c|}{$\begin{array}{l}\text { External validation } \\
\text { cohort }\end{array}$} \\
\hline & & No.p & & No.p & & No. & \\
\hline \multirow[t]{2}{*}{ age } & $<60$ & 274 & 24.8 & 103 & 19.2 & 18 & 39.1 \\
\hline & $\geq 60$ & 829 & 75.2 & 433 & 80.8 & 28 & 60.9 \\
\hline \multirow[t]{3}{*}{ race } & White & 808 & 73.3 & 430 & 80.2 & & \\
\hline & Black & 152 & 13.8 & 50 & 9.3 & & \\
\hline & Others & 143 & 13.0 & 56 & 10.4 & & \\
\hline \multirow[t]{2}{*}{ sex } & Female & 729 & 16.3 & 434 & 81.0 & 26 & 56.5 \\
\hline & Male & 374 & 83.7 & 102 & 19.0 & 20 & 43.5 \\
\hline \multirow[t]{2}{*}{ Tumor grade } & $\begin{array}{l}\text { Well/ } \\
\text { moderate }\end{array}$ & 631 & 57.2 & 319 & 59.5 & 12 & 26.1 \\
\hline & $\begin{array}{l}\text { Poor/ } \\
\text { undifferentiated }\end{array}$ & 472 & 42.8 & 217 & 40.5 & 34 & 73.9 \\
\hline \multirow[t]{4}{*}{$\mathrm{T}$} & $\mathrm{T} 1$ & 124 & 11.2 & 58 & 10.8 & 0 & 0.0 \\
\hline & $\mathrm{T} 2$ & 564 & 51.1 & 198 & 36.9 & 0 & 0.0 \\
\hline & T3 & 391 & 35.4 & 268 & 50.0 & 46 & 100.0 \\
\hline & $\mathrm{T} 4$ & 24 & 2.2 & 12 & 2.2 & 0 & 0.0 \\
\hline \multirow[t]{2}{*}{ M } & MO & 881 & 79.9 & 464 & 86.6 & 44 & 95.7 \\
\hline & M1 & 222 & 20.1 & 72 & 13.4 & 2 & 4.3 \\
\hline \multirow{3}{*}{$\begin{array}{l}\text { Regional } \\
\text { nodes } \\
\text { examined }\end{array}$} & $\geq 6$ & 135 & 12.2 & 64 & 11.9 & 16 & 34.8 \\
\hline & $1-5$ & 408 & 37.0 & 253 & 47.2 & 25 & 54.3 \\
\hline & 0 & 560 & 50.8 & 219 & 40.9 & 5 & 10.9 \\
\hline \multirow{4}{*}{$\begin{array}{l}\text { Regional } \\
\text { nodes } \\
\text { positive }\end{array}$} & 0 & 275 & 24.9 & 157 & 29.3 & 19 & 41.3 \\
\hline & $1-3$ & 234 & 21.2 & 140 & 26.1 & 21 & 45.7 \\
\hline & $\geq 4$ & 34 & 3.1 & 20 & 3.7 & 6 & 13.0 \\
\hline & No examined & 560 & 50.8 & 219 & 40.9 & 0 & 0.0 \\
\hline \multirow{2}{*}{$\begin{array}{l}\text { Liver } \\
\text { metastasis }\end{array}$} & Absent & 959 & 86.9 & 484 & 90.3 & 16 & 34.8 \\
\hline & Present & 144 & 13.1 & 52 & 9.7 & 30 & 65.2 \\
\hline
\end{tabular}




\section{Table.1 Patients characteristics}

\begin{tabular}{|llllllll|}
\hline Tumor size & $1-13 \mathrm{~mm}$ & 146 & 13.2 & 71 & 13.2 & 0 & 0.0 \\
\cline { 2 - 8 } & $14-63 \mathrm{~mm}$ & 800 & 72.5 & 399 & 74.4 & 37 & 80.4 \\
& $\geq 64 \mathrm{~mm}$ & 157 & 14.2 & 66 & 12.3 & 9 & 19.6 \\
\hline
\end{tabular}


Table.2 Baseline demographic and tumor characteristics of patients based on tumor size.

\begin{tabular}{|c|c|c|c|c|c|c|}
\hline \multicolumn{7}{|c|}{ Tumor size } \\
\hline Characteristic & & $\begin{array}{l}1- \\
13 \mathrm{~mm}\end{array}$ & $\begin{array}{l}14- \\
63 \mathrm{~mm}\end{array}$ & $\geq 64 \mathrm{~mm}$ & $\begin{array}{l}\text { Log- } \\
\text { rank }\end{array}$ & $\begin{array}{l}\mathrm{P} \\
\text { value }\end{array}$ \\
\hline \multirow[t]{2}{*}{ age } & $<60$ & $38(26.0)$ & $190(23.8)$ & $46(29.3)$ & 2.292 & 0.318 \\
\hline & $\geq 60$ & 108(74.0) & $610(76.3)$ & $111(70.7)$ & & \\
\hline \multirow[t]{3}{*}{ race } & White & 118(80.8) & $575(71.9)$ & $115(73.2)$ & 5.996 & 0.199 \\
\hline & Black & 17(11.6) & $115(14.4)$ & $20(12.7)$ & & \\
\hline & Others & $11(7.5)$ & $110(13.8)$ & $22(14.0)$ & & \\
\hline \multirow[t]{2}{*}{ sex } & Female & $84(57.5)$ & $539(67.4)$ & $106(67.5)$ & 5.501 & 0.064 \\
\hline & Male & $62(42.5)$ & $261(32.6)$ & $15(32.5)$ & & \\
\hline \multirow[t]{2}{*}{ grade } & $\begin{array}{l}\text { Well/ } \\
\text { moderate }\end{array}$ & $110(75.3)$ & $445(55.6)$ & $76(48.4)$ & 25.399 & $\stackrel{<}{<.001}$ \\
\hline & $\begin{array}{l}\text { Poor/ } \\
\text { undifferentiated }\end{array}$ & $36(24.7)$ & $355(44.4)$ & 81(51.6) & & \\
\hline \multirow[t]{4}{*}{ T stage } & $\mathrm{T} 1$ & 45(30.8) & $71(8.9)$ & $8(5.1)$ & 157.654 & $\begin{array}{l}< \\
0.001\end{array}$ \\
\hline & $\mathrm{T} 2$ & $81(55.5)$ & $446(55.8)$ & $37(23.6)$ & & \\
\hline & T3 & $20(13.7)$ & 265(33.1) & $106(67.5)$ & & \\
\hline & $\mathrm{T} 4$ & $0(0)$ & $18(2.3)$ & $6(3.8)$ & & \\
\hline \multirow[t]{2}{*}{ M stage } & MO & 132(90.4) & 635(79.4) & $114(72.6)$ & 15.358 & $\begin{array}{l}< \\
0.001\end{array}$ \\
\hline & M1 & $14(9.6)$ & $165(20.6)$ & $43(27.4)$ & & \\
\hline \multirow[t]{3}{*}{$\begin{array}{l}\text { Regional nodes } \\
\text { examined }\end{array}$} & $\geq 6$ & $10(6.8)$ & 103(12.9) & $22(14.0)$ & 32.032 & $\begin{array}{l}< \\
0.001\end{array}$ \\
\hline & $1-5$ & $84(57.5)$ & $266(33.3)$ & $58(36.9)$ & & \\
\hline & 0 & $52(35.6)$ & $431(53.9)$ & $77(49.0)$ & & \\
\hline \multirow[t]{4}{*}{$\begin{array}{l}\text { Regional nodes } \\
\text { positive }\end{array}$} & 0 & $77(52.7)$ & $170(21.3)$ & 28(17.8) & 77.146 & $\begin{array}{l}< \\
0.001\end{array}$ \\
\hline & $1-3$ & 17(11.6) & $172(21.5)$ & $45(28.7)$ & & \\
\hline & $\geq 4$ & $0(0)$ & $27(3.4)$ & $7(4.5)$ & & \\
\hline & No examined & $52(35.6)$ & $431(53.9)$ & $77(49.0)$ & & \\
\hline
\end{tabular}


Table.2 Baseline demographic and tumor characteristics of patients based on tumor size.

Liver metastasis

Absent

139(95.2)

694(86.8)

126(80.3)

14.994

0.001

Present

$7(4.8)$

$106(13.3)$

31(19.7) 
Table.3 Univariate and multivariate cancer-specific survival analyses for the influence of tumor size in gallbladder cancer.

\begin{tabular}{|c|c|c|c|c|c|}
\hline \multirow[t]{2}{*}{ Variable } & & \multicolumn{2}{|c|}{ Univariable analysis } & \multicolumn{2}{|c|}{ Multivariable analysis } \\
\hline & & HR (95\% Cl) & $\mathrm{P}$ & HR (95\% Cl) & $\mathrm{P}$ \\
\hline \multirow[t]{2}{*}{ age } & $<60$ & Reference & $<.001$ & Reference & $\begin{array}{l}< \\
0.001\end{array}$ \\
\hline & $\geq 60$ & $\begin{array}{l}1.599(1.316- \\
1.942)\end{array}$ & & $\begin{array}{l}1.426(1.168- \\
1.741)\end{array}$ & \\
\hline \multirow[t]{3}{*}{ race } & White & Reference & 0.243 & & \\
\hline & Black & $\begin{array}{l}0.827(0.651- \\
1.049)\end{array}$ & & & \\
\hline & Others & $\begin{array}{l}0.901(0.704- \\
1.153)\end{array}$ & & & \\
\hline \multirow[t]{2}{*}{ sex } & Female & Reference & 0.694 & & \\
\hline & Male & $\begin{array}{l}0.967(0.819- \\
1.142)\end{array}$ & & & \\
\hline \multirow[t]{2}{*}{ Tumor grade } & $\begin{array}{l}\text { Well/ } \\
\text { moderate }\end{array}$ & Reference & $<.001$ & Reference & $\begin{array}{l}< \\
0.001\end{array}$ \\
\hline & $\begin{array}{l}\text { Poor/ } \\
\text { undifferentiated }\end{array}$ & $\begin{array}{l}1.724(1.472- \\
2.018)\end{array}$ & & $\begin{array}{l}1.346(1.141- \\
1.589)\end{array}$ & \\
\hline \multirow[t]{4}{*}{ T stage } & T1 & Reference & $<.001$ & Reference & $\begin{array}{l}< \\
0.001\end{array}$ \\
\hline & $\mathrm{T} 2$ & $\begin{array}{l}2.406(1.659- \\
3.488)\end{array}$ & & $\begin{array}{l}2.079(1.425- \\
3.033)\end{array}$ & \\
\hline & T3 & $\begin{array}{l}5.986(4.124- \\
8.689)\end{array}$ & & $\begin{array}{l}3.682(2.483- \\
5.460)\end{array}$ & \\
\hline & $\mathrm{T} 4$ & $\begin{array}{l}7.597(4.314- \\
13.379)\end{array}$ & & $\begin{array}{l}7.458(4.133- \\
13.456)\end{array}$ & \\
\hline \multirow[t]{2}{*}{ M stage } & MO & Reference & $<.001$ & Reference & $\begin{array}{l}< \\
0.001\end{array}$ \\
\hline & M1 & $\begin{array}{l}3.826(3.202- \\
4.572)\end{array}$ & & $\begin{array}{l}2.427(2.007- \\
2.935)\end{array}$ & \\
\hline \multirow[t]{2}{*}{$\begin{array}{l}\text { Regional nodes } \\
\text { examined }\end{array}$} & $\geq 6$ & Reference & $<.001$ & Reference & $\begin{array}{l}< \\
0.001\end{array}$ \\
\hline & $1-5$ & $\begin{array}{l}0.977(0.745- \\
1.280)\end{array}$ & & $\begin{array}{l}1.132(0.835- \\
1.534)\end{array}$ & \\
\hline
\end{tabular}




\begin{tabular}{|c|c|c|c|c|c|}
\hline & 0 & $\begin{array}{l}1.706(1.323- \\
2.198)\end{array}$ & & $\begin{array}{l}2.673(1.905- \\
3.751)\end{array}$ & \\
\hline \multirow[t]{4}{*}{$\begin{array}{l}\text { Regional nodes } \\
\text { positive }\end{array}$} & 0 & Reference & $<.001$ & Reference & $\dot{0} 0001$ \\
\hline & $1-3$ & $\begin{array}{l}2.786(2.142- \\
3.624)\end{array}$ & & $\begin{array}{l}1.817(1.387- \\
2.380)\end{array}$ & \\
\hline & $\geq 4$ & $\begin{array}{l}3.604(2.322- \\
5.592)\end{array}$ & & $\begin{array}{l}2.040(1.255- \\
3.316)\end{array}$ & \\
\hline & No examined & $\begin{array}{l}3.088(2.445- \\
3.901)\end{array}$ & & $\begin{array}{l}2.673(1.905- \\
3.751)\end{array}$ & \\
\hline \multirow[t]{3}{*}{ Tumor size } & $1-13 \mathrm{~mm}$ & Reference & $<0.001$ & Reference & 0.001 \\
\hline & $14-63 \mathrm{~mm}$ & $\begin{array}{l}2.496(1.836- \\
3.392)\end{array}$ & & $\begin{array}{l}1.552(1.132- \\
2.127)\end{array}$ & \\
\hline & $\geq 64 \mathrm{~mm}$ & $\begin{array}{l}4.244(2.993- \\
6.019)\end{array}$ & & $\begin{array}{l}2.043(1.418- \\
2.943)\end{array}$ & \\
\hline
\end{tabular}

\section{Figures}


SEER Research Database (1975-2016)

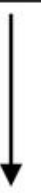

Gallbladder cancer identified by Site recode ICO-0-3( $\mathrm{n}=25297)$

Gallbladder cancer after surgery included ( $\mathrm{n}=7361$ )

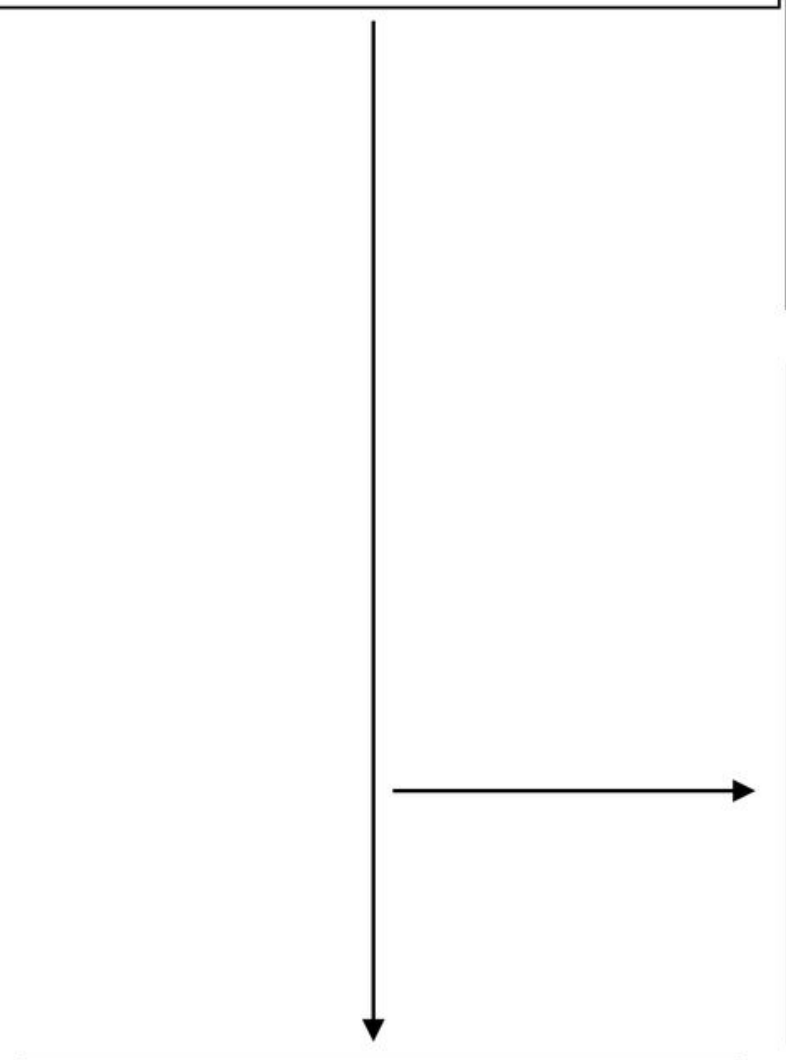

Exclusion $(\mathrm{n}=17936)$

- Survival months flag: incomplete dates or not calculated $(\mathrm{n}=3528)$

- Diagnosis confirmation: clinical diagnosis only or unknown $(n=300)$

- Tumor sequence number $\neq$ One primary only $(\mathrm{n}=3869)$

- ICD-O-3 histology chodes $\neq 8010,8148$, $8503,8470,8140,8144,8480,8310,8490$, $8070,8560,8020,8246,8041,8013,8244$, $8503,(\mathrm{n}=2565)$

- Surgery performed or unknown $(\mathrm{n}=7674)$

\section{Exclusion $(\mathrm{n}=5722)$}

- Tumor size 0 or unknown ( $\mathrm{n}=4297)$

- Regional nodes examined unknown or unperformed $(\mathrm{n}=65)$

- Others: regional lymph nodes positive unknown $(\mathrm{n}=1)$, Tumor grade unknown $(\mathrm{n}=113)$, incomplete TNM staging system $(\mathrm{n}=1208)$, race unknown $(\mathrm{n}=11)$, cancerspecific survival missing or unknown $(\mathrm{n}=17)$, no detail tumor size $(\mathrm{n}=5)$ and liver metastasis $(\mathrm{n}=5)$

In this analysis $(\mathrm{n}=1639)$

\section{Figure 1}

Flowchart displaying the extraction process of resected GBC cases in SEER database. 

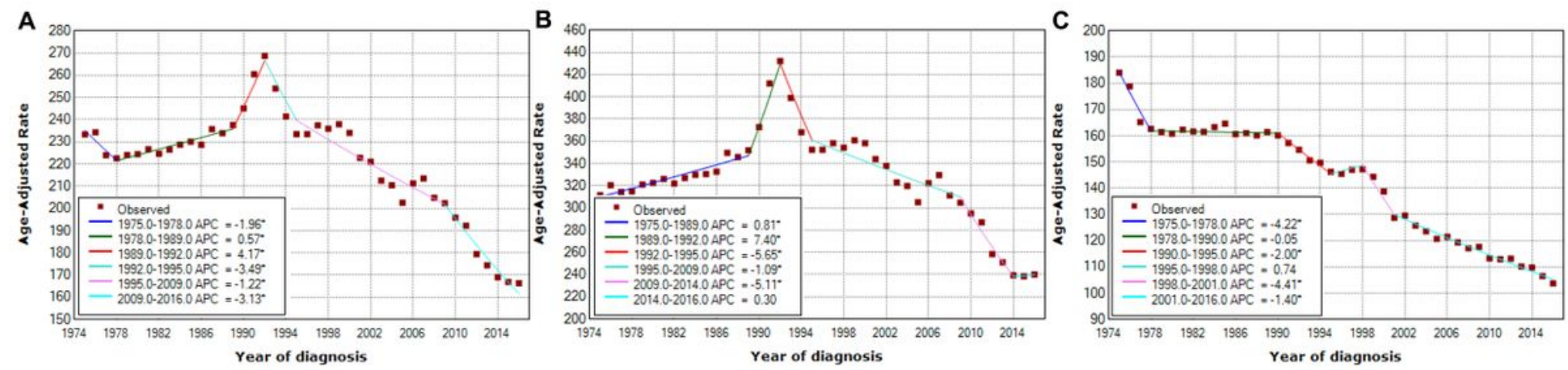

Figure 2

GBC incidence trends by overview (A), Male(B), Female(C) recorded in 18 registries of the SEER database, 1975 to 2016 . Annual percentage change (APC) significantly different than zero at the $5 \%$ level, calculated based on a two-sided t test.
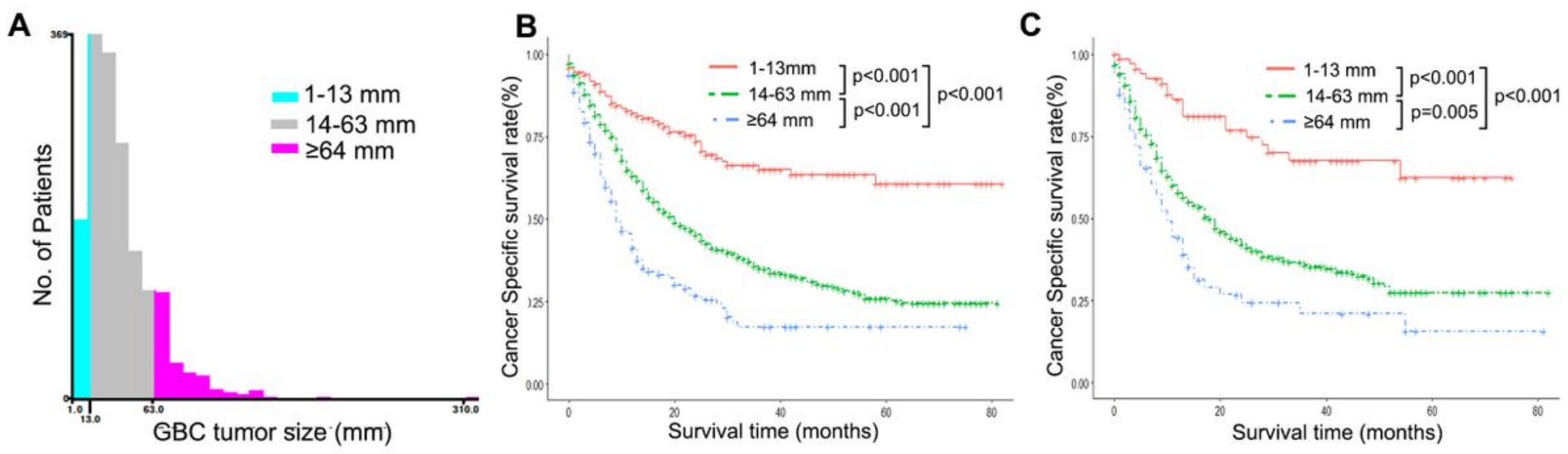

Figure 3

X-tile analysis was done on patient data from the SEER registry. $(A)$ is shown on a histogram of the entire cohort. Cancer-specific survival rates for GBC patients in training cohort (B) and validation cohort (C). 
A

Points

\begin{tabular}{|c|c|c|c|c|c|c|c|c|c|}
\hline 1 & 2 & 3 & 4 & 5 & 6 & 7 & 8 & 9 & 10 \\
\hline
\end{tabular}

Age

Tumor grade

T

M

$\begin{array}{cc}<60 & \geq 60 \\ \begin{array}{c}\text { Well' } \\ \text { moderate }\end{array} & \begin{array}{c}\text { Poorl undiffereniated } \\ \end{array}\end{array}$

Regional nodes

examined

Regional nodes

positive

\begin{tabular}{cccc} 
T1 & T2 & T3 & T4 \\
\hline
\end{tabular}

Tumor size

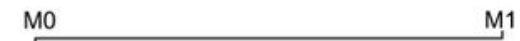

$\begin{array}{lll}\geq & 1-5 & 0\end{array}$

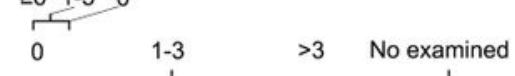

Total points

1-year CSS

3-year CSS

5-year CSS
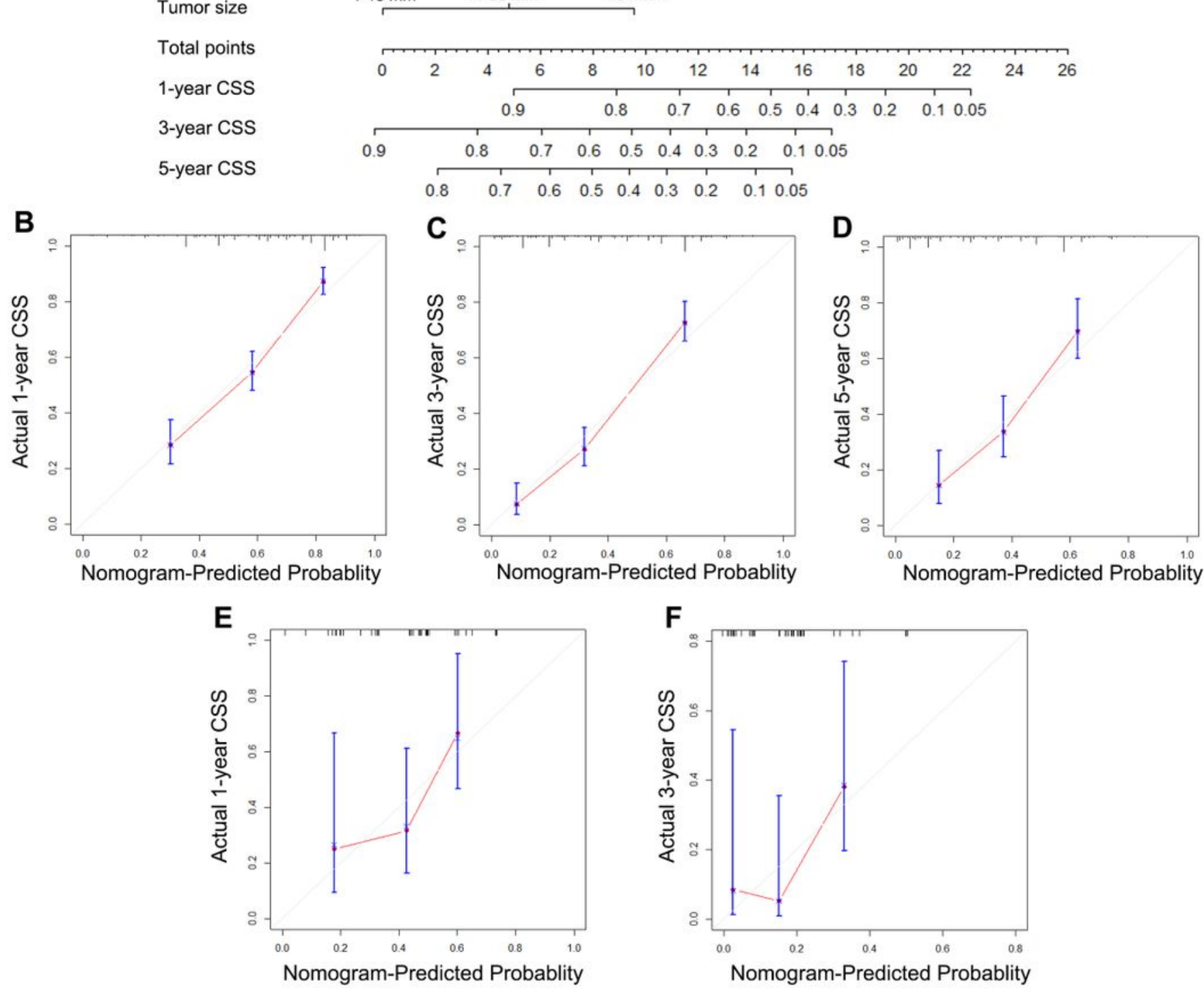

\section{Figure 4}

A nomogram predicting 1-,3- and 5-year CSS of patients with resected GBC. (A). Calibration curves for 1-, 3and 5-year CSS $(B, C, D)$ using validation cohort are shown. External validation using calibration plots for predicting 1- and 3- CSS of GBC (E, F). 

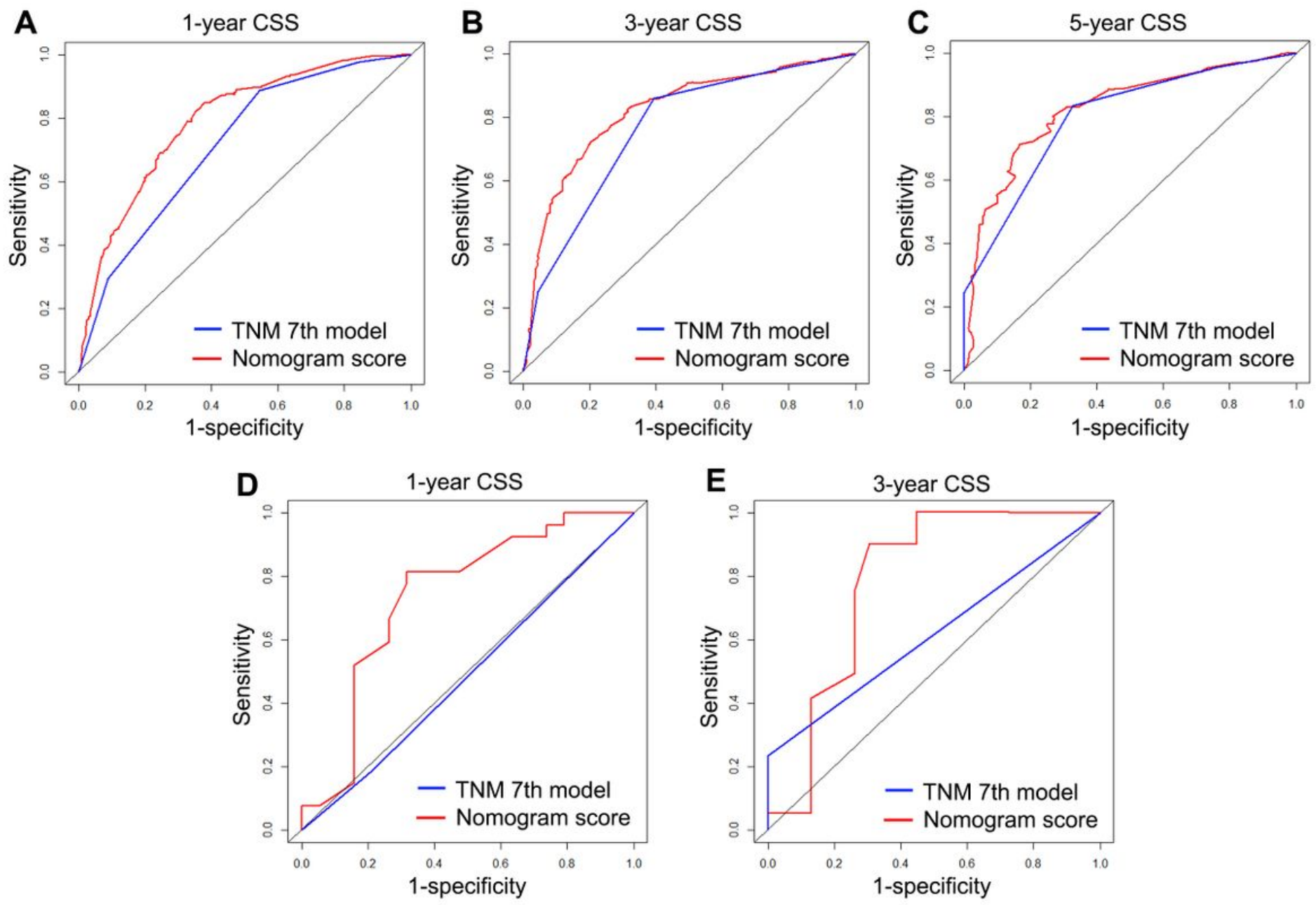

\section{Figure 5}

Comparison of the ROC curves of the nomogram and the TNM stage system for 1-,3- and 5-year CSS in validation cohort (A, B, C) and for 1- and 3-year CSS external validation cohort (D, E). 